\title{
Neural systems supporting and affecting economically relevant behavior
}

\author{
This article was published in the following Dove Press journal: \\ Neuroscience and Neuroeconomics \\ 14 May 2012 \\ Number of times this article has been viewed
}

\section{Sven Braeutigam}

Oxford Centre for Human Brain Activity, University of Oxford, Oxford, United Kingdom
Correspondence: Sven Braeutigam Oxford Centre for Human Brain Activity, University of Oxford, Oxford OX3 7JX, United Kingdom

Tel +44018 65283816

Fax +4401865793101

Email sven.braeutigam@ohba.ox.ac.uk

\begin{abstract}
For about a hundred years, theorists and traders alike have tried to unravel and understand the mechanisms and hidden rules underlying and perhaps determining economically relevant behavior. This review focuses on recent developments in neuroeconomics, where the emphasis is placed on two directions of research: first, research exploiting common experiences of urban inhabitants in industrialized societies to provide experimental paradigms with a broader real-life content; second, research based on behavioral genetics, which provides an additional dimension for experimental control and manipulation. In addition, possible limitations of stateof-the-art neuroeconomics research are addressed. It is argued that observations of neuronal systems involved in economic behavior converge to some extent across the technologies and paradigms used. Conceptually, the data available as of today raise the possibility that neuroeconomic research might provide evidence at the neuronal level for the existence of multiple systems of thought and for the importance of conflict. Methodologically, Bayesian approaches in particular may play an important role in identifying mechanisms and establishing causality between patterns of neural activity and economic behavior.
\end{abstract}

Keywords: neuroeconomics, behavioral genetics, decision-making, consumer behavior, neural system

\section{Introduction}

From ancient bartering to global markets, human activity that consists of producing, exchanging, distributing, and consuming of goods and services, ie, economically relevant behavior, was, is, and will be an important driver of societies. Since the inception of market research about a hundred years ago, theorists and traders alike have tried to unravel and understand the mechanisms and hidden rules underlying and perhaps determining such behavior. Over the last ten years or so, multidisciplinary research commonly known as neuroeconomics ${ }^{1}$ has skyrocketed, whereby several hundreds of research papers as well as many books have been published addressing the neural basis of economic behavior.

Numerous and partly overlapping reviews have appeared, summarizing the general aspects of the discipline of neuroeconomics and its position within a broader scientific framework. ${ }^{2-4}$ Several reviews consider research at the intersection of specific but not necessarily unrelated issues, such as financial decision-making, ${ }^{5}$ marketing and market research (commonly referred to as neuromarketing), ${ }^{6,7}$ consumer choice theory, ${ }^{8}$ intertemporal decision-making (choices among options, the effects of which occur at different moments), ${ }^{9,10}$ social interactions, ${ }^{11}$ morality, ${ }^{12}$ uncertainty, ${ }^{13}$ valuation, ${ }^{14}$ evolutionary game theory, ${ }^{15}$ and organizational neuroscience. ${ }^{16}$ Possible implications 
for law-making and policy-making as well as ethics have also been addressed in review papers, ${ }^{17,18}$ and so have the technologies used in neuroeconomic research (Figure 1). ${ }^{19,20}$ At present, there is general consensus that understanding more about how the brain functions should help in the pursuit of understanding economic behavior.

However, important challenges have been posed regarding the validity and generalizability of the insight gained. In particular, a criticism has been made that all that neuroeconomic research has been able to identify so far has been the brain regions that appear to be activated in response to certain mental processes, decisions, choices, or responses to reward stimuli. In other words, most of the evidence accumulated to date is of correlation, making the interpretation of causality difficult, if not impossible. ${ }^{21-24}$

The purpose of this review is to shed some light on recent developments in the field, while also addressing the possible limitations of state-of-the-art neuroeconomics research. The emphasis is placed on two not necessarily independent directions of research. First, there is research exploiting common experiences of urban inhabitants in industrialized societies to provide experimental paradigms with a broader real-life content, such as shopping and watching television. This research relates to the increasing use of virtual reality-like technologies as a means to address questions of ecological validity and experimental control in psychology and neuroscience research. ${ }^{25-28}$ Second, there is neuroeconomic research based on behavioral genetic methodologies. There is growing evidence that the molecular makeup of cognitive processes varies between individuals due to systematic genetic factors. Consequently, there is growing consensus that biological factors associated with individual variance should be included in order to strengthen the conclusions drawn and to improve the theories derived from neuroeconomics research. ${ }^{29,30}$

\section{Studies with a broader real-life content}

In this section, three studies are reviewed that feature stimuli based on real material encountered in day-to-day life. Directly related studies are summarized in Table 1, and Figure 2 shows an overview of the brain areas mentioned in the text.

Knutson et $\mathrm{al}^{31}$ have used functional magnetic resonance imaging to study the neuronal mechanisms of subjects' purchasing decisions in a shopping task. In this task, the subjects saw a real product (eg, Godiva chocolate), followed by the price of the product (product and price displayed), followed by a cue asking them whether or not they would buy the product (product, price, and cue displayed). After experimentation, subjects rated each item for desirability (product preference) and the price they would be willing to pay for the product (price differential $=$ "price willing to pay" - "price displayed during scan"). Note that both measures correlated with the decision to buy, ie, preferred and cheap items were less likely to be rejected.

Using these measures as input variables for the functional magnetic resonance imaging data, the authors observed that product preference correlated positively with nucleus accumbens activation during the product period as well as

EEG Electroencephalography is perhaps the oldest of all noninvasive electrophysiologic recording techniques, used for the first time in the late 1920s. EEG is sensitive to so-called secondary currents that are detectable as electrical potential differences on the scalp. The secondary currents are a consequence of primary intercellular currents associated with synaptic transmission between nerve cells. Conceptually, EEG and magnetoencephalography are related technologies; however, the EEG signal is affected to a larger degree by tissue and skull inhomogeneities compared with magnetoencephalography, implying reduced signal quality as well more complex source models for data analysis.

MEG Magnetoencephalography is a neuroimaging method based on the detection of the magnetic fields that are generated by the currents flowing in neurons. MEG is preferentially sensitive to magnetic fields generated in the cerebral cortex, but modern, wholehead systems employing multiple sensor configurations can detect activity in subcortical regions. Neural field changes are extremely small, necessitating specific and expensive detectors that operate at cryogenic temperature and respond to the changes in magnetic flux through the loops. MEG is thought to be a relatively direct measure of cell communication along neural pathways. Importantly, the MEG detectors are sensitive to field changes occurring over timescales of milliseconds to seconds, thus complementing fMRI, which is sensitive to longer-term changes.

fMRI Functional magnetic resonance imaging is by far the most common method of imaging human brain activity. At the heart of this technique is the weak dependence of the magnetic resonance signal on the oxygenation level of the blood, which in turn depends on the brain activity. $\mathrm{fMRI}$ is capable of providing millimeter-scale functional images of the level of activity in the brain but with time resolution limited to the rate at which the oxygenation levels changes, ie, of the order of seconds. The technique has been used extensively to study the neural mechanisms associated with a wide range cognitive tasks. To date, fMRI technology has reached a high level of sophistication, and powerful analysis packages exist facilitating, to some extent standardized approaches to neuroimaging.

Figure I Brief outline of neuroimaging technologies mentioned in the text. ${ }^{19,20,79}$ 
Table I Overview of selected studies based on real-world material or genetic/pharmacological principles (in alphabetical order)

\begin{tabular}{|c|c|c|c|}
\hline Author & Issue for research & Method & Result \\
\hline Barraza et al ${ }^{63}$ & Oxytocin & Drug study & Oxytocin increases charitable donations \\
\hline Baumgartner et $\mathrm{al}^{64}$ & Oxytocin & $\begin{array}{l}\text { fMRI; } \\
\text { drug study }\end{array}$ & $\begin{array}{l}\text { Oxytocin alters trust adaptation and amygdala } \\
\text { activation }\end{array}$ \\
\hline Camille et $\mathrm{al}^{70}$ & $\begin{array}{l}\text { Subjective value of food options } \\
\text { during choices }\end{array}$ & Lesion study & $\begin{array}{l}\text { Ventromedial frontal lobe damage disrupts } \\
\text { consistency of choice }\end{array}$ \\
\hline Frydman et $a l^{60}$ & MAOA-L/H polymorphism & Genotyping & $\begin{array}{l}\text { MAOA-H carriers are more risk averse compared } \\
\text { with MAOA-L carriers }\end{array}$ \\
\hline Hare et $\mathrm{al}^{32}$ & $\begin{array}{l}\text { Subjective value of food options } \\
\text { during choices }\end{array}$ & fMRI & $\begin{array}{l}\text { Differential representation of goal and decision } \\
\text { values in the orbitofrontal cortex }\end{array}$ \\
\hline Morris et $\mathrm{al}^{44}$ & $\begin{array}{l}\text { Neural correlates of television } \\
\text { commercials }\end{array}$ & fMRI & $\begin{array}{l}\text { Activations in inferior frontal and middle temporal } \\
\text { gyri correlate with AdSAM }{ }^{\circledR} \text { pleasure scores, } \\
\text { whereas activations in superior temporal and } \\
\text { middle frontal gyri correlate with arousal }\end{array}$ \\
\hline Ohme et $\mathrm{al}^{46}$ & $\begin{array}{l}\text { Neural correlates of television } \\
\text { commercials }\end{array}$ & EEG & $\begin{array}{l}\text { Frontal asymmetries are sensitive to the emotional } \\
\text { but not informational parts of advertisements }\end{array}$ \\
\hline Plassmann et $\mathrm{al}^{33}$ & $\begin{array}{l}\text { Modulators of experienced } \\
\text { pleasantness }\end{array}$ & fMRI & $\begin{array}{l}\text { Wine price correlates with flavor pleasantness and } \\
\text { activation in medial orbitofrontal cortex }\end{array}$ \\
\hline Stanton et $\mathrm{al}^{61}$ & $\begin{array}{l}\text { Testosterone; inverted } \\
U \text { association }\end{array}$ & Blood assay & $\begin{array}{l}\text { High and low testosterone levels reduce aversion } \\
\text { to economic risk }\end{array}$ \\
\hline Vecchiato et $\mathrm{al}^{43}$ & $\begin{array}{l}\text { Neural correlates of television } \\
\text { commercials }\end{array}$ & EEG & $\begin{array}{l}\text { Frontal asymmetries correlate with experienced } \\
\text { pleasantness }\end{array}$ \\
\hline Zak et al ${ }^{62}$ & Testosterone & Drug study & $\begin{array}{l}\text { High testosterone level diminishes generosity } \\
\text { in the ultimatum game }\end{array}$ \\
\hline
\end{tabular}

Notes: AdSAM ${ }^{\circledR}$, Advertisement Self-Assessment Manikins (visual technique to assess emotional responses); MAOA-L/H, gene encoding for monoamine oxidase-A, an enzyme regulating the catabolism of neurotransmitters, including serotonin and dopamine (MAOA-H allele exhibit higher expression of the enzyme); oxytocin, neuromodulatory hormone associated with behaviors, such as pair bonding, anxiety and social recognition; testosterone, potent steroid hormone.

Abbreviations: EEG, electroencephalogram; fMRI, functional magnetic resonance imaging.

subsequent price period, while the price differential correlated positively with activation of the mesial prefrontal cortex. Taking into account trial outcome, the authors observed that nucleus accumbens activation during the product period and mesial prefrontal cortex activation during the price period significantly predicted (ie, correlated with) the subsequent decision to buy, while insula activation during the price period predicted a subsequent decision not to buy. Drawing on known functional neuroanatomy, the authors have argued that distinct neural mechanisms associated with anticipation and evaluation of gains and losses may precede as well as support the buying decisions of consumers.

Despite convincing evidence provided by Knutson et al, ${ }^{31}$ their observations have partly been challenged by a conceptually similar study employing additional (experimental) incentives over and above product and price. ${ }^{32}$ The choices of participant were driven by the price differential; however, activity in the ventral striatum (nucleus accumbens) correlated with prediction error (trial sequence effect) but not measures of product preference. This was contrary to the results reported by Knutson et al, ${ }^{31}$ but consistent with a study where subjects rated flavor-liking and taste intensity of wines. ${ }^{33}$
At present, it is not fully understood what causes these discrepancies. However, it would be reasonable to assume that a precise functional role of a brain region in economic decision-making or other cognitive process is, at least to some degree, task-dependent. ${ }^{34}$

According to this view, each region assumes a specific role within a dynamic neuronal network best suited to determine the optimal course of action given the specific requirements posed by a task or real-life situation. Interestingly, Knutson et $\mathrm{al}^{31}$ found activation in several brain regions to be correlated with their behavioral measures; however, activation in those areas did not add to the ability of the hypothesized brain activation variables (nucleus accumbens, mesial prefrontal cortex, and insula) to predict purchasing. Such noncentral "players" are commonly observed in a variety studies, possibly reinforcing the notion that the precise functional significance of brain regions is determined by network architecture.

The next paper mentioned investigates the neuronal response in subjects choosing between house options identified by their monthly mortgages. The authors explored the temporal dynamics of decision biases, ie, when bias starts to influence decision-making processes. 


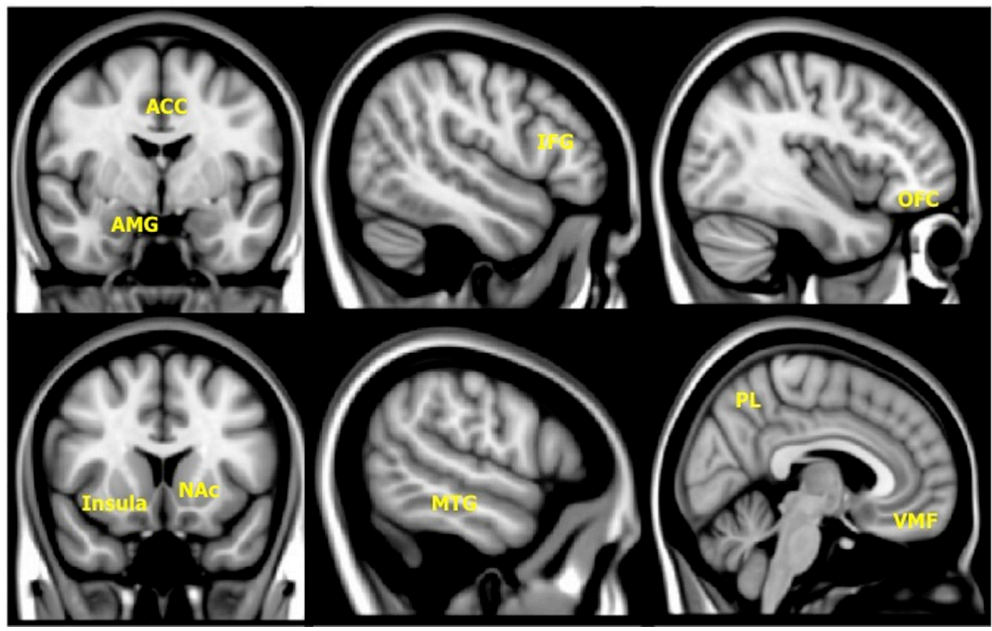

\begin{tabular}{|l|l|}
\hline Anterior cingulate cortex & $\begin{array}{l}\text { Frontal part of the cingulate cortex. Implicated in functions central to intelligent behavior, such } \\
\text { as emotional self-control, error recognition, problem-solving, and adaptive response to changing } \\
\text { conditions. }\end{array}$ \\
\hline Amygdala & $\begin{array}{l}\text { The amygdaloid nuclei lie in the temporal lobe, and belong functionally with the limbic system. } \\
\text { Implicated in the processing of emotional response and memory. }\end{array}$ \\
\hline Inferior frontal gyrus & $\begin{array}{l}\text { Encompasses motor speech area of Broca for the (language) dominant hemisphere of the brain. } \\
\text { Implicated in the inhibition of prepotent responses and risk aversion (right inferior frontal gyrus). }\end{array}$ \\
\hline Insula & $\begin{array}{l}\text { A cortical component of the limbic system. Thought to be associated with visceral functions such } \\
\text { as autonomic and emotional response, including a role in self-awareness and interpersonal } \\
\text { experience. }\end{array}$ \\
\hline Middle temporal gyrus & $\begin{array}{l}\text { Part of the lateral temporal lobe. Thought to have a role in memory recall, access } \\
\text { of meaning and semantic analysis. }\end{array}$ \\
\hline Nucleus accumbens & $\begin{array}{l}\text { Part of the ventral striatum receiving extensive cortical projections. Implicated in the processing of } \\
\text { reward, novelty, and salience. }\end{array}$ \\
\hline Orbitofrontal cortex & $\begin{array}{l}\text { Part of an extensive area known as the prefrontal association cortex. Thought to have a regulatory } \\
\text { role of a person's feeling, judgment and initiative. }\end{array}$ \\
\hline Parietal lobe & $\begin{array}{l}\text { Assumed to play a role in higher order integration of cognitive processes, motor planning (posterior } \\
\text { parts, these are also termed association cortices), and processing of complex sensory input } \\
\text { (anterior parts). }\end{array}$ \\
\hline Ventromedial frontal region & $\begin{array}{l}\text { Part of the prefrontal cortex. The term is used differently by different researchers, but usually } \\
\text { includes Brodmann area 10. Assumed to play a critical role in decision-making, and in the } \\
\text { processing of fear. }\end{array}$ \\
\hline
\end{tabular}

Figure 2 Brain areas mentioned in the text.

Notes: These areas have been implicated in but are not limited to economically relevant behavior. Each structure is found in both hemispheres. The structural images are based on the Montreal Neurological Institute template brain. For the purpose of this overview, the mesial prefrontal cortex is included in the ventromedial frontal region. The functional significance of brain areas is not universally agreed upon, and this overview should be seen as a rough rather than definite guide. General references for functional neuroanatomy are Snell ${ }^{47}$ and England and Wakely. ${ }^{80}$

Hedgcock et $\mathrm{al}^{35}$ have used magnetoencephalography to study the neural mechanisms associated with buying decisions that have potentially long-term consequences. In a simplified property scenario, the subjects were given the choice to buy an expensive apartment (high monthly mortgage repayment) located in a safe neighborhood (low crime rate) or to buy a cheap apartment located in less safe area (modest crime rate). In some trials, the subjects were presented with a third option, which was to buy an apartment in the modest crime rate area at a price slightly higher than the cheap apartment but still much less than the expensive apartment, thus biasing low-price purchases.
The authors found that brain signals observed over the right frontal and, to some extent, parietal regions, differed significantly during the $800 \mathrm{msec}$ following (choice-inducing) stimulus onset when subjects chose an expensive compared with a cheap apartment, as well as when subjects considered choice sets with a bias versus choice sets without a bias. These differences in neural activity contrasted with much longer response times, between about 3.5 and 8 seconds. The authors speculated that these differences, possibly generated in the dorsolateral prefrontal cortices, would be consistent with rule-based decision processes, whereby choice is driven by experimental bias. Note that the authors did not perform 
source analyses of their magnetoencephalography data, thus making these sensor-space localizations speculative.

Despite some limitations, these results are consistent with the assumption that choice-making is associated with a dynamic and complex neural network. ${ }^{20,36}$ In particular, the frontoparietal network observed here is broadly in line with a previous magnetoencephalography study of the neural response elicited in subjects shopping for common grocery items. ${ }^{37}$ Interestingly, such networks appear to be equally involved, irrespective of whether a decision has putatively limited (grocery item) or obvious long-term significance (house buying). Note that Braeutigam et al also observed early choice as well as gender-specific neural activity $(500-800 \mathrm{msec})$ that contrasted with much longer response times $(2.5 \mathrm{sec}){ }^{37}$

The timing of such an outcome-specific neuronal response is consistent with a number of well documented components typically associated with higher-order processes, such as executive control of attention and formation of new semantic memories. ${ }^{38,39}$ Nevertheless, the speed of network activity observed in these magnetoencephalography studies is intriguing. Differences in the neural response correlate with trial outcome as early as a few tenths of a second after presentation of choice options, and several seconds before the decision is communicated. It is noteworthy that a delay of similar length has also been found in an otherwise unrelated study, where the outcome of a decision appeared to be encoded in brain activity of the prefrontal and parietal cortices up to several seconds before it entered awareness. ${ }^{40}$

The last paper in this section addresses the neuronal correlates of memory encoding in the context of advertisements, thereby looking at processes that typically precede and possibly influence a purchasing decision at a later point in time.

Astolfi et $\mathrm{al}^{41}$ used high-resolution electroencephalography to investigate the neural mechanisms underlying memory encoding of television commercials. In this experiment, the subjects viewed a series of documentaries over several days. Television commercials were adapted and embedded in the documentaries to mimic a natural television-viewing experience. The clips advertised well known international brands, but were not broadcast in the country where the study was performed in order to reduce the likelihood of confounding encoding and recognition effects. Several days after watching the documentaries, a controlled memory test was conducted to assess how many and in what detail the television clips were remembered.

Analyzing spectral densities, the authors found significantly increased activity in the frontal and parietal cortices for subsequently remembered television commercials (recall of both brand name and specific sequences) compared with forgotten advertisements. The results obtained from a connectivity analysis suggested that the parietal regions received significantly more inflow bilaterally (strength of connectivity to the parietal regions) from other cortical areas for remembered compared with forgotten clips. Despite strong results, the authors were modest in concluding that their study sheds some light on the neural networks underlying memorization of television commercials.

This study illustrates a larger class of investigations, many of which are performed by neuromarketing companies these days. Despite the complexity of the issue at hand, there is converging evidence that the neuronal response can reliably differentiate between television advertisements or parts thereof (sometimes called "branding" moments ${ }^{42}$ ) along several, partly overlapping dimensions, such as subsequent recall, pleasantness, ${ }^{43}$ arousal, ${ }^{44}$ and emotional valence. ${ }^{45,46}$ The marker signals are consistently identified in the frontal and temporal lobes, although the parietal cortex may also play an important role in processing scenes that are special in some sense.

Speculatively, a deeper understanding of such frontal and parietal networks could help to establish links between watching an advertisement and subsequently deciding to purchase the product being advertised. Perhaps the most interesting and encouraging aspect is that such identifications can be made using naturalistic and variable stimuli, without the exact control of stimulus properties and task parameters omnipresent in traditional cognitive experiments. However, it remains to be seen the extent to which the neural correlates of television advertisements, or other clips meant to inform and influence behavior (eg, the British Heart Foundation's hands-only resuscitation campaign), can explain and predict subsequent decision-making or an individual response.

\section{Studies based on genetic and/or pharmacological principles}

In this section, three studies are reviewed that employed methodologies based on behavioral genetics, with particular emphasis on the dopaminergic system in the brain. Dopamine is a neurotransmitter, which is released in the prefrontal cortex amongst other structures. The prefrontal cortex is an important structure in the neuroanatomical pathways mediating functions such as working memory, reward processing, and emotion regulation. Dopamine is released in the prefrontal cortex as well as other structures within 
these pathways. ${ }^{47}$ The relationship between dopamine and prefrontal cortical function can be conceptualized as an inverted U curve, whereby too little or too much dopamine signaling is known to impair working memory and adversely affect reward-processing. ${ }^{48}$ Both genetic and pharmacological factors can affect dopamine metabolism, and therefore the position of the individual on the curve. In particular, but not exclusively, dopamine degradation in frontal brain areas is dependent on catechol-O-methyltransferase (COMT) enzyme activity. COMT activity, in turn, is substantially affected by a specific genetic polymorphism (a variation at a chromosome locus within the population), resulting in a substitution of valine (Val) and methionine (Met) amino acids. As a consequence, COMT activity is higher in homozygous individuals carrying two Val alleles compared with individuals with two Met alleles, implying higher dopamine levels in the latter population because the enzyme breaking down dopamine is less active. ${ }^{49}$ However, it is not fully understood how this genetic polymorphism may affect cognitive performance. The summary in Table 2 may serve as an overview of current issues for research, where the evidence is still incomplete or even contradictory. ${ }^{49-52}$

In what follows, three studies are presented first before being discussed. These studies are based on gambling tasks commonly found in experimental economics. Directly related studies are summarized in Table 1.

Krugel et $\mathrm{a}^{53}$ used functional magnetic resonance imaging to study the effect of COMT genotype on the neural response in subjects performing a probabilistic learning task. The task was to win as many points (converted into money afterwards) as possible by learning to choose on each trial the most profitable among four symbols, where the most profitable symbol would change over the whole experiment. Val-COMT subjects won significantly more points than Met-COMT individuals, although the effect size was only moderate (approximately 4\%). A reinforcement-learning model (each choice was followed by an outcome stimulus informing about the current value of the symbol) was fitted to the subjects' choices in order to obtain trial-by-trial estimates of individual prediction errors and learning rates to be used as covariates in the functional magnetic resonance

Table 2 Overview of current unresolved issues for research

\begin{tabular}{ll}
\hline Met-COMT $>$ Val-COMT & Val-COMT $>$ Met-COMT \\
\hline Cognitive flexibility & Emotional processing \\
Working memory & Task switching \\
\hline
\end{tabular}

Note: ">" indicates hypothesized superior task performance.

Abbreviations: COMT, catechol-O-methyltransferase; Met, methionine; Val, valine. imaging data analysis. Compared with Met-COMT subjects, Val-COMT individuals showed significantly stronger correlations between prediction errors and striatal activity, and between learning rates and changes in effective connectivity between the striatum and prefrontal cortex.

The authors have argued that their results underline the critical role of dopamine in comparing expectation and outcome in order to optimize upcoming decisions. This insight might prove to be important in unraveling the neural mechanisms supporting rapid and flexible decision-making in response to changing reward contingencies.

The next study focuses on the neurophysiological responses to gains and losses within the context of a gambling task not requiring the subjects to learn strategies.

Marco-Pallarés et $\mathrm{al}^{54}$ used electroencephalography to investigate the effect of COMT genotype on the neural response in subjects performing a simplified version of a gambling task originally used by Gehring and Willoughby. ${ }^{55}$ In this task, two gray boxes were shown on a screen, with ' 5 ' or ' 25 ' shown within each box. The subject selected one box, and the choice meant they are gambling either 5 or 25 $€$ cent. Once the choice was made, the boxes changed color, either to red (indicating a loss) or to green (indicating a win). Replicating the original finding reported by Gehring and Willoughby, ${ }^{55}$ Marco-Pallarés et al ${ }^{54}$ observed a medial-frontal negativity that was higher in amplitude following losses compared with gains at about $280 \mathrm{msec}$ after outcome-stimulus onset. No source analysis of the medial-frontal negativity was performed, making it impossible to localize the medialfrontal negativity observed here precisely, although the signal topographies reported by Marco-Pallarés et $\mathrm{al}^{54}$ are consistent with a generator in the anterior cingulate cortex as identified by Gehring and Willoughby. ${ }^{55}$

Regarding possible COMT effects, the authors found a significant outcome by genotype interaction, reflecting larger differences between medial-frontal negativity amplitudes elicited by losses and gains in Val-COMT individuals compared with Met-COMT individuals. Interestingly, a significant valence by genotype interaction was also found for beta-band $(20-30 \mathrm{~Hz})$ oscillatory brain activity over the frontal brain regions, reflecting larger differences between beta power elicited by gains and losses in Val-COM individuals compared with Met-COMT individuals (note gain-beta was less than loss-beta). In the absence of differences in choice behavior between the groups of subjects, the authors concluded that their study provides evidence that the brain electric activity response to monetary gains and losses is modulated by COMT activity. The dissociation between 
medial-frontal negativity and beta findings might further suggest that COMT genotype is associated with several independent electrophysiological markers.

The last study presented here differs from the two previous ones in that COMT enzyme activity was pharmacologically altered. Tolcapone is a brain-penetrant COMT inhibitor, which leads to observable cognitive, behavioral, and neurochemical effects in animals and humans. ${ }^{56}$

Farrell et $\mathrm{al}^{57}$ used the original Gehring and Willoughby $\operatorname{task}^{55}$ to study the effect of COMT genotype and pharmacological intervention on making bets. The authors found a significant genotype by drug interaction. On placebo, Val-COMT subjects are more likely (approximately 11\%) than Met-COMT subjects to make a large rather than a small bet. On tolcapone, this difference is reversed, making Val-COMT subjects significantly more risk-averse compared with those given placebo (risk aversion is defined here as the proportion of small bets). Importantly, the same pattern of making bets was also observed for trials following two wins or two losses, or other combinations of prior outcomes.

The authors have argued that their findings directly support the inverted $U$ model of dopamine function in decision-making and reward, where COMT appears to affect the "trait" of, eg, risk-averseness, rather than sensitivity to losses versus rewards. In accordance with this, Met-COMT subjects are maximally risk-averse given their genetic imprint, but move "downhill" under the influence of tolcapone to become less risk-averse. In contrast, Val-COMT subjects are suboptimally risk-averse, and move "uphill" to become maximally risk-averse (Figure 3).

Taken together, these studies suggest that COMT genotype can affect behavior in an economically relevant context, but the precise nature and consistency of this effect remains unclear. In particular, Farrell et al $^{57}$ did, but Marco-Pallarés et $\mathrm{al}^{54}$ did not, observe an effect of COMT genotype on making risky decisions, despite nearly identical experimental settings in both studies. However, the former study used a richer set of choice outcomes, originally proposed by Gehring and Willoughby, ${ }^{55}$ such as "correct loss" (lost but could have lost more), in addition to binary win or loss trials. Arguably, this manipulation may alter perceived incentives such that the COMT effect comes to the fore. In other words, although the propensity for making risky choices is somehow "hard-wired" in the genes, a specific context is required in order to trigger the behavior.

At the neural level, these studies provide further evidence that COMT genotype is associated with identifiable and partly interpretable marker signals. In particular, the results obtained by Krugel et $\mathrm{al}^{53}$ are in line with recent studies suggesting that the ventral striatum plays a critical role in evaluating prediction errors in order to inform future decisions. ${ }^{32,58,59}$

Note that at least one further genetic polymorphism identified by Frydman et $\mathrm{a}^{60}$ to affect dopamine catabolism has been shown to influence decision-making under risk. Interestingly, Frydman et al observed increased risk aversion in individuals with high monoamine oxidase A activity

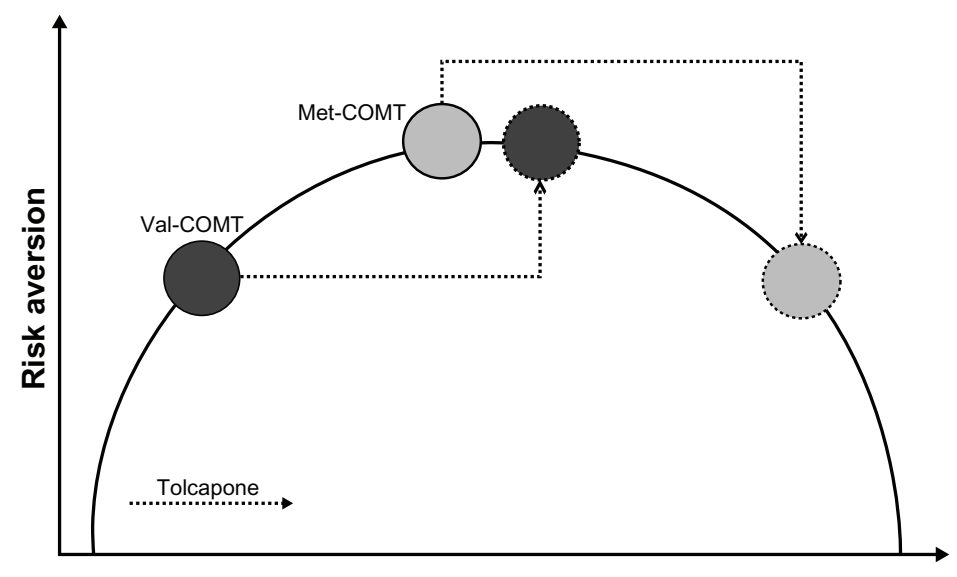

Cortical dopamine

Figure 3 COMT genotype and the dopaminergic inverted $U$ curve. Val-COMT subjects (black circle) have higher COMT enzyme activity and thus lower dopamine tone than Met-COMT subjects (gray circle).

Notes: After tolcapone (a COMT inhibitor; dotted lines), all subjects move to the right because dopamine tone increases. However, the functional correlates of this shift differ between genotypes. Val-COMT subjects move closer to the maximum, becoming more risk-averse, whereas Met-COMT subjects are now to the right of the peak, hence are less risk-averse. ${ }^{57}$

Abbreviations: COMT, catechol-O-methyltransferase; Met, methionine; Val, valine. 
compared with individuals with low activity of this enzyme. At the level of enzyme action, this appears opposite to the observation by Farrell et $\mathrm{al}^{57}$ of increased risk aversion in individuals with low COMT activity because both enzymes break down dopamine. However, it remains to be determined whether this apparent incompatibility can be explained in terms of substrate specificity (given that monoamine oxidase A also catabolizes serotonin) and the precise neural circuitry involved.

In addition, the steroid hormone testosterone has been implicated in risk-taking, where risk aversion is highest for, an "optimal" level of testosterone, but risk aversion is reduced for either higher or lower levels. ${ }^{61}$ This would be consistent with an inverted $U$ relationship broadly similar to the relationship between dopamine and prefrontal cortical function.

Over and above risk-taking, testosterone may affect generosity. ${ }^{62}$ Generosity as well as trust may also be affected by the neuromodulatory hormone oxytocin, ${ }^{63,64}$ commonly associated with behaviors such as pair bonding, anxiety, and social recognition. These findings provide further evidence that economically relevant behavior is supported by a multitude of neurotransmitters and hormones possibly operating at different levels. Although progress is clearly being made (eg, in the area of dopamine and oxytocin interactions ${ }^{65}$ ), still very little is known about the precise nature of the mutual actions of such systems. Nevertheless, it appears that genetic factors might explain some of the individual variability in the behavior of decision-makers commonly observed in experimental games.

\section{Addressing the limitations}

This section reviews three not necessarily independent approaches to remedy a central limitation of neuroeconomics research. Namely, most of the evidence so far is correlational, thus making it difficult to identify mechanisms and establish causality between patterns of neural activity and economic behavior.

First, researchers should use rigorous experimental designs and analytical methods in order to rule out alternative explanations for the observed data. Traditional approaches have been immensely successful in unraveling the mechanisms underlying human behavior and brain function, and should be further pursued. In this context, it would be worth investigating the extent to which probabilistic theories of human reasoning could contribute to an understanding of economic behavior. According to this approach, the errors and biases documented for ostensibly logical tasks occur because individuals import their everyday uncertain strategies into the laboratory. ${ }^{66}$ Conceivably, such theories may help to unravel, for example, the neuronal mechanisms associated with computation of goal value (reward associated with outcome), decision value (benefits minus costs), and prediction error (deviation from expected reward) that are necessary for economic decision-making, but possibly correlated with each other, depending on the experimental design. ${ }^{32}$ In other words, one may hope to resolve which strategies are employed in decision-making.

Second, research should directly address the issue of drawing conclusions about real decisions based on hypothetical reports of intended behavior. Hypothetical choices are often employed in neuroscience experiments when implementing real choice is impractical or unethical. However, relatively little is known about how insight into neural processing in hypothetical choice tasks might generalize to real choice.

In this context, a functional magnetic resonance imaging study by Jeong Kang et al ${ }^{67}$ required subjects to make hypothetical (trial did not count) and real (2\% likelihood that trial would be implemented as real) purchasing decisions. The authors observed that activity in the common areas of the orbitofrontal cortex and the ventral striatum correlated with behavioral measures of the stimulus value (broadly similar to the price differential as used by Knutson et $\mathrm{al}^{31}$ ) of the goods in both types of decision, but activity in these regions was stronger in the real choice condition. Despite substantial overlap in neural activity between hypothetical and real choices, there were also apparent differences. Most notably, some areas of the anterior cingulate cortex exhibited stronger functional connectivity with orbitofrontal cortices in the real trials than in the hypothetical trials.

These findings suggest that conclusions about neural circuitry drawn from hypothetical choice might generalize to real choice when purchasing consumer goods, but some issues remain. Apart from not receiving every product they "bought", the subjects did not spend their own money but received an endowment at the beginning of the experiment. Such manipulations are common practice in neuroimaging studies of purchasing behavior, but this might change the perceived reference point against which choice options are evaluated, which in turn can alter the neuronal response. ${ }^{68}$

Third, researchers should utilize a mathematical framework known as Bayesian inference. Accordingly, a large number of correlations, if available, can be exploited to 
support reverse inference, ie, inferring the likelihood of a cognitive process from a pattern of brain activity. ${ }^{69}$ The nucleus accumbens may serve as an illustration here. ${ }^{6}$ The goal is to estimate the probability of a reward process given nucleus accumbens activation, $P(R \mid N)$. As shown in the Appendix, this probability can be expressed in terms of the probability of nucleus accumbens activation given a reward task, $P(N \mid R)$, the probability of nucleus accumbens activation given a nonreward task, $P(N \mid \bar{R})$, and the prior probability of a reward task, $P(R)$.

$P(N \mid R)$ and $P(N \mid \bar{R})$ can be estimated using meta-analytical techniques, ie, by counting how often nucleus accumbens activation was observed in representative samples of studies employing and not employing reward tasks. $P(R)$ is variable and needs to be guessed or somehow estimated by the experimenter, and this estimate could be wrong. However, $P(R \mid N)$ is largely independent of the prior probability as long as it is relatively unlikely to observe nucleus accumbens activation in a nonreward compared with a reward task (see Figure 4). This is an important point, highlighting the strength of Bayesian approaches. Under suitable conditions, unknown or difficult to estimate quantities become irrelevant and final inferences robust.

An example is presented here. Using $P(N \mid R)=0.937$ and $P(N \mid \bar{R})=0.046\left(\right.$ data based on well over 1000 publications $\left.^{6}\right)$, $P(R \mid N)$ is larger than 0.8 for all prior probabilities 0.3 and above ( $Q \sim 0.1$, Figure 4$)$. The Bayes factor in this case is 0.86 . In other words, although nucleus accumbens activation is not necessarily observed in studies utilizing a reward task (in about $40 \%$ of such studies), there is moderate almost strong evidence to infer reward-related processes when observing nucleus accumbens activation. Note that Bayesian approaches work best in conjunction with specific questions and hypothesis. A question like "What is the probability of any brain region to be activated in any given task?" might be too broad/general.

\section{General discussion}

From a brain mapping point of view, observations of neuronal systems involved in economic behavior appear to converge across imaging modalities and a variety of different experimental tasks. Neuronal activity specific to choice-making and decision-making is commonly observed in, amongst others, the ventral striatum, amygdala, anterior cingulate cortex, and parietal and frontal cortices. Moreover, at least some of these locations are consistent with a recent lesion study reporting less consistent behavior in patients with ventromedial frontal lobe damage deciding on choice sets comprising food items and drinks compared with healthy control subjects. ${ }^{70}$ Interestingly, but perhaps not surprisingly, broadly similar networks are identified using paradigms based on television advertisements involving less stringent control over stimulus properties and task conditions.

Perhaps most interesting from a conceptual point of view are common observations of differences in the neuronal response that correlate with choice outcome long before the behavioral response, and even before information (eg, price) relevant to choice-making is available. Essentially, the

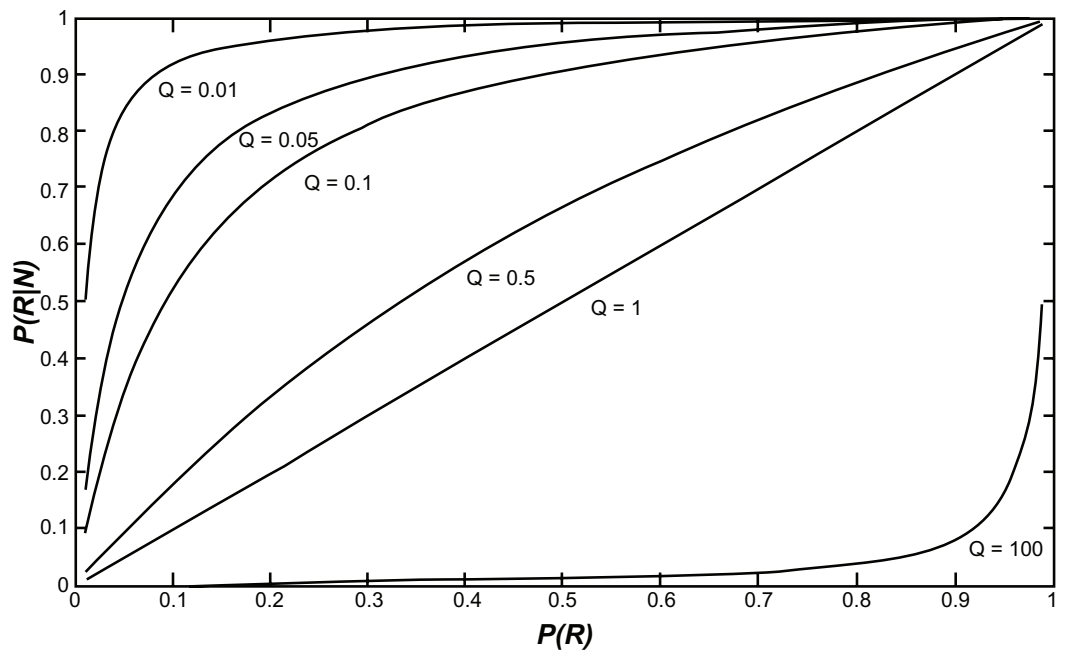

Figure 4 Reverse inference.

Notes: The posterior probability $P(R \mid N)$ is shown as a function of the prior probability $P(R)$. For small values of $Q=P(N \mid \bar{R}) / P(N \mid R)$, the posterior probability is approximately constant except for small values of $P(R)$. For large values of $Q$, the posterior probability is approximately constant except for high values of $P(R)$. The curve for large $Q$ is included for illustration, but is not relevant in this context.

Abbreviations: $N$, nucleus accumbens activation; $R$, reward process or task (see text and the appendix for details). 
significance of such "early" neuronal activity is unresolved, as to what processes may be occurring during the time between divergence of neuronal response and the decision. However, these responses appear to reflect higher order cognitive processes outside awareness, raising the intriguing possibility that economically relevant behavior is, to some extent, decided upon long before it becomes manifest. If so, a deeper understanding of these early neuronal systems might yield insight into why consumers are typically unaware of the relative importance of different product attributes affecting their perceptions of the attractiveness of their choice options. ${ }^{71}$

One may speculate whether such putative processes outside awareness are indicative of multiple systems of decision and choice at the neuronal level. It is generally agreed that there is substantial behavioral evidence for the existence of multiple systems of thought and for the importance of conflict. $^{72}$ This would be in line with the assumption that decision-making and choice-making is a highly conditional form of information-processing sensitive to a variety of endogenous and exogenous factors, such as anticipated reward, framing, and time pressure. ${ }^{73,74}$ However, at present, there is an apparent absence of repeated studies providing evidence for localized neuronal correlates for multiple systems, supporting an alternative assumption that a unitary system can account for decision-making. ${ }^{75}$

In answering these questions, behavioral genetics might provide important clues, by showing which polymorphisms can affect economic behavior, and where there is synergy or competition of genetic factors. The following would be a hypothetical scenario, partly supported by the data available to date. Dopamine-catabolizing enzymes A (monoamine oxidase A) and B (COMT) are controlled by two genetic polymorphisms, with low activity variants, ie, $\mathrm{A}_{\text {low }}$ and $\mathrm{B}_{\text {low }}$, respectively. $\mathrm{A}_{\text {low }}$ decreases and $\mathrm{B}_{\text {low }}$ increases risk aversion, the effect on working memory is synergistic, with carriers of both $\mathrm{A}_{\text {low }}$ and $\mathrm{B}_{\text {low }}$ alleles showing a marked increase in performance scores, ${ }^{76}$ and risk aversion correlates with working memory load. ${ }^{77}$

Assuming that issues of substrate specificity and neuronal circuitry can be resolved, it might then be possible to establish consistency of observations for $\mathrm{A}_{\text {low }}$, in that increased ability to cope with working memory supports risky decisions, whereas $\mathrm{B}_{\text {low }}$ might constitute a contradiction (despite the ability to cope with load, risk aversion rises). This, in turn, could be interpreted as evidence for at least two conflicting neural systems not easily reconciled within a single unitary framework.

Despite encouraging progress and convergences across the different approaches, it has to be acknowledged that there remain seemingly contradictory observations across studies, and the reasons for such discrepancies need to be determined. Ultimately, it might not be possible to know which mental processes are encoded in or mediated by activation in a given brain area without knowing the exact context, experimental or real-life, in which observations are made. Over and above individual brain regions and neurotransmitter systems, it appears that network dynamics is key, whereby approaches aimed at classification of statistical associations among activation patterns will become increasingly important in research trying to understand and predict economically relevant behavior.

\section{Acknowledgments}

The author thanks Louisa Coulson and Elizabeth Tunbridge for the feedback and comments on the manuscript. This work was supported by the Department of Psychiatry, University of Oxford, UK.

\section{Disclosure}

The author reports no conflict of interest in this work.

\section{References}

1. Clithero JA, Tankersley D, Huettel SA. Foundations of neuroeconomics: from philosophy to practice. PLoS Biol. 2008;6:2348-2353.

2. Camerer CF. Neuroeconomics: Opening the grey box. Neuron. 2008;60:416-419.

3. Loewenstein G, Rick S, Cohen JD. Neuroeconomics. Annu Rev Psychol. 2008;59:647-672.

4. Glimcher PW, Rustichini A. Neuroeconomics: the consilience of brain and decision. Science. 2004;306:447-452.

5. Bossaerts P. What decision neuroscience teaches us about financial decision making. Annual Review of Financial Economics. 2009;1:383-404.

6. Ariely D, Berns GS. Neuromarketing: the hope and hype of neuroimaging in business. Nat Rev Neurosci. 2010;11:284-292.

7. Lee N, Broderick AJ, Chamberlain L. What is neuromarketing? A discussion and agenda for future research. Int J Psychophysiol. 2007;63:199-204.

8. Hands DW. Economics, psychology and the history of consumer choice theory. Camb J Econ. 2010;34:633-648.

9. Kalenscher T, Pennartz CMA. Is a bird in the hand worth two in the future? The neuroeconomics of intertemporal decision-making. Prog Neurobiol. 2008;84:284-315.

10. Schüll ND, Zaloom C. The shortsighted brain: neuroeconomics and the governance of choice in time. Soc Stud Sci. 2011;41:515-538.

11. Fehr F, Camerer CF. Social neuroeconomics: the neural circuitry of social preferences. Trends Cogn Sci. 2007;11:419-427.

12. Kvaran T, Sanfey AG. Toward an integrated neuroscience of morality: the contribution of neuroeconomics to moral cognition. Top Cogn Sci. 2010;2:579-595.

13. Platt ML, Huettel SA. Risky business: the neuroeconomics of decision making under uncertainty. Nat Neurosci. 2008;11:398-403.

14. Rangel A, Camerer C, Montague PR. A framework for studying the neurobiology of value-based decision making. Nat Rev Neurosci. 2008;9:545-556.

15. Schipper BC. On an evolutionary foundation of neuroeconomics. Econ Philos. 2008;24:495-513. 
16. Becker WJ, Cropanzano R, Sanfey AG. Organizational neuroscience: taking organizational theory inside the neural black box. J Manage. 2011;37:933-961.

17. Goodenough OR, Tucker M. Law and cognitive neuroscience. Annu Rev Law Soc Sci. 2010;6:61-92.

18. Kenning P, Linzmajer M. Consumer neuroscience: an overview of an emerging discipline with implications for consumer policy. Journal of Consumer Protection and Food Safety. 2010;6:111-125.

19. Kable JW. The cognitive neuroscience toolkit for the neuroeconomist: a functional overview. J Neurosci Psychol Econ. 2011;4:63-84.

20. Vecchiato G, Astolfi L, de Vico Fallani F, et al. On the use of EEG or MEG brain imaging tools in neuromarketing research. Comput Intell Neurosci. 2011;10:1-12.

21. Harrison GW. Neuroeconomics: a critical reconsideration. Econ Philos. 2008;24:303-344.

22. Camerer CF. The potential of neuroeconomics. Econ Philos. 2008; 24:369-379.

23. Dagher A. Shopping centers in the brain. Neuron. 2007;53:7-8.

24. Birnberg JG, Ganguly AR. Is neuroaccounting waiting in the wings? An essay. Accounting, Organizations and Society. 2012;37:1-13.

25. Bohil CJ, Alicea B, Biocca FA. Virtual reality in neuroscience, research and therapy. Nat Rev Neurosci. 2011;12:752-762.

26. Burgess PW, Alderman N, Evans J, Emslie H, Wilson BA. The ecological validity of tests of executive function. $J$ Int Neuropsychol Soc. 1998;4:547-558.

27. Stores G, Crawford C, Selman J, Wiggs L. Home polysomnography norms for children. Technol Health Care. 1998;6:231-236.

28. Eysenck MW, Keane MT. Cognitive Psychology. 2nd ed. Philadelphia, PA: Taylor \& Francis; 2000.

29. Ramsøy TZ, Skov M. How genes make up your mind: individual biological differences and value-based decisions. J Econ Psychol. 2010;31:818-831.

30. Zyphur MJ, Narayanan J, Arvey RD, Alexander GJ. The genetics of economic risk preferences. J Behav Decis Mak. 2009;22:367-377.

31. Knutson B, Rick S, Wimmer E, Prelec D, Loewenstein G. Neural predictors of purchase. Neuron. 2007;53:147-156.

32. Hare TA, O'Doherty J, Camerer CF, Schultz W, Rangel A. Dissociating the role of the orbitofrontal cortex and the striatum in the computation of goal values and prediction errors. J Neurosci. 2008;28: 5623-5630.

33. Plassmann H, Doherty J, Shiv B, Rangel A. Marketing actions can modulate neural representations of experienced pleasantness. Proc Natl Acad Sci U SA. 2008;105:1050-1054.

34. Engel AK, Fries P, Singer W. Dynamic predictions: oscillations and synchrony in top-down processing. Nat Rev Neurosci. 2001;2:704-716.

35. Hedgcock WM, Crowe DA, Leuthold AC, Georgopoulos AP. A magnetoencephalography study of choice bias. Exp Brain Res. 2010;202:121-127.

36. Braeutigam S. Neuroeconomics: from neural systems to economic behavior. Brain Res Bull. 2005;67:355-360.

37. Braeutigam S, Rose SPR, Swithenby SJ, Ambler T. The distributed neuronal systems supporting choice-making in real-life situations: differences between men and women when choosing groceries detected using magnetoencephalography. Eur J Neurosci. 2004;20: 293-302.

38. Polich J. Updating P300: an integrative theory of P3a and P3b. Clin Neurophysiol. 2007;118:2128-2148.

39. Rugg MD. Memory and consciousness: a selective review of issues and data. Neuropsychologia. 1995;33:1131-1141.

40. Soon CS, Brass M, Heinze HJ, Haynes JD. Unconscious determinants of free decisions in the human brain. Nat Neurosci. 2008;11: $543-545$.

41. Astolfi L, de Vico Fallani F, Cincotti F, et al. Neural basis for brain responses to TV commercials: a high-resolution EEG study. IEEE Trans Neural Syst Rehabil Eng. 2008;16:522-531.

42. Young C. Brain waves, picture sorts ${ }^{\circledR}$, and branding moments. J Advert Res. 2002;42:42-53.
43. Vecchiato G, Toppi J, Astolfi L, et al. Spectral EEG frontal asymmetries correlate with the experienced pleasantness of TV commercial advertisements. Med Biol Eng Comput. 2011;49:579-583.

44. Morris JD, Klahr NJ, Shen F, et al. Mapping a multidimensional emotion in response to television commercials. Hum Brain Mapp. 2009;30:789-796.

45. Ioannides AA, Liu L, Theofilou D, et al. Real time processing of affective and cognitive stimuli in the human brain extracted from MEG signals. Brain Topogr. 2000;13:11-19.

46. Ohme R, Reykowska D, Wiener D, Choromanska A. Application of frontal EEG asymmetry to advertising research. J Econ Psychol. 2010;31:785-793.

47. Snell RS. Clinical Neuroanatomy for Medical Students. 3rd ed. Boston, MA: Little, Brown and Company; 1998.

48. Cools R, D'Esposito M. Inverted-U-shaped dopamine actions on human working memory and cognitive control. Biol Psychiatry. 2011;69:113-125.

49. Tunbridge EM, Harrison PJ, Weinberger DR. Catechol-Omethyltransferase, cognition, and psychosis: Val ${ }^{158} \mathrm{Met}$ and beyond. Biol Psychiatry. 2006;60:141-151.

50. Barnett JH, Scoriels L, Munafo MR. Meta-analysis of the cognitive effects of the catechol-O-methyltransferase gene val158/108met polymorphism. Biol Psychiatry. 2008;64:137-144.

51. Barnett JH, Jones PB, Robbins TW, Müller U. Effects of the catechol$\mathrm{O}$-methyltransferase $\mathrm{Val}^{158} \mathrm{Met}$ polymorphism on executive function: a meta-analysis of the Wisconsin Card Sort Test in schizophrenia and healthy controls. Mol Psychiatry. 2007;12:502-509.

52. Nagel IE, Chicherio C, Li S-C, et al. Human aging magnifies genetic effects on executive functioning and working memory. Front Hum Neurosci. 2008;2:1-8.

53. Krugel LK, Biele G, Mohr PNC, Li SC, Heekeren HR. Genetic variation dopaminergic neuromodulation influences the ability to rapidly and flexibly adapt decisions. Proc Natl Acad Sci U S A. 2009;106:17951-17956.

54. Marco-Pallarés J, Cucurell D, Cunillera T, et al. Genetic variability in the dopamine system (dopamine receptor D4, catechol-Omethyltransferase) modulates neurophysiological responses to gains and losses. Biol Psychiatry. 2009;66:154-161.

55. Gehring WJ, Willoughby AR. The medial frontal cortex and the rapid processing of monetary gains and losses. Science. 2002;295:2279-2282.

56. Roussos P, Giakoumaki SG, Bitsios P. Tolcapone effects on gating, working memory, and mood interact with the synonymous catecholO-methyltransferase rs $4818 \mathrm{c} / \mathrm{g}$ polymorphism. Biol Psychiatry. 2009;66:997-1004.

57. Farrell SM, Tunbridge EM, Braeutigam S, Harrison P. COMT Val158Met denotype determines the direction of cognitive effects produced by catechol-O-methyltransferase inhibition. Biol Psychiatry. 2012;71:538-544.

58. Staudinger MR, Erk S, Abler B, Walter H. Cognitive reappraisal modulates expected value and prediction error encoding in the ventral striatum. Neuroimage. 2009;47:713-721.

59. Yacubian J, Gläscher J, Schroeder K, Sommer T, Braus DF, Büchel C. Dissociable systems for gain- and loss-related value predictions and errors of prediction in the human brain. J Neurosci. 2006;26:9530-9537.

60. Frydman C, Camerer C, Bossaerts P, Rangel A. MAOA-L carriers are better at making optimal financial decisions under risk. Proc Biol Sci. 2011;278:2053-2059.

61. Stanton SJ, Mullette-Gillman OA, McLaurin RE. Low- and hightestosterone individuals exhibit decreased aversion to economic risk. Psychol Sci. 2011;22:447-453.

62. Zak PJ, Kurzban R, Ahmadi S, et al. Testosterone administration decreases generosity in the ultimatum game. PLoS One. 2009;4:e8330.

63. Barraza JA, McCullough ME, Ahmadi S, Zak PJ. Oxytocin infusion increases charitable donations regardless of monetary resources. Horm Behav. 2011;60:148-151. 
64. Baumgartner T, Heinrichs M, Vonlanthen A, Fischbacher U, Fehr E. Oxytocin shapes the neural circuitry of trust and trust adaptation in humans. Neuron. 2008;58:639-650.

65. Baskerville TA, Douglas AJ. Dopamine and oxytocin interactions underlying behaviors: potential contributions to behavioral disorders. CNS Neurosci Ther. 2010;16:92-123.

66. Oaksford M, Chater N. The probabilistic approach to human reasoning. Trends Cogn Sci. 2001;5:349-357.

67. Jeong Kang MJ, Rangel A, Camus M, Camerer CF. Hypothetical and real choice differentially activate common valuation areas. J Neurosci. 2011;31:461-468.

68. De Martino B, Kumaran D, Holt B, Dolan RJ. The neurobiology of reference-dependent value computation. J Neurosci. 2009;29: 3833-3842.

69. Poldrack RA. Inferring mental states from neuroimaging data: from reverse inference to large-scale decoding. Neuron. 2011;72:692-697.

70. Camille N, Griffiths CA, Vo K, Fellows LK, Kable JW. Ventromedial frontal lobe damage disrupts value maximization in humans. J Neurosci. 2011;31:7527-7532.

71. Dhar R, Simonson I. The effect of forced choice on choice. J Marketing Res. 2003;40:146-160.

72. Kahneman D. Maps of bounded rationality: psychology for behavioral economics. Am Econ Rev. 2003;93:1149-1475.
73. Bettman JR, Luce MF, Payne JW. Constructive consumer choice processes. J Consum Res. 1998;25:187-217.

74. Slovic P. The construction of preference. Am Psychol. 1995;50: 364-371.

75. Kahneman D. Remarks on neuroeconomics. In: Glimcher PW, Camerer CF, Fehr E, Poldrack RA, editors. Neuroeconomics. London, UK: Elsevier; 2009

76. Barnett JH, Xu K, Heron J, Goldman D, Jones PB. Cognitive effects of genetic variation in monoamine neurotransmitter systems: A populationbased study of COMT, MAOA, and 5HTTLPR. Am J Med Genet B Neuropsychiatr Genet. 2010;156:158-167.

77. Whitney P, Rinehart CA, Hinson JM. Framing effects under cognitive load: the role of working memory in risky decisions. Psychon Bull Rev. 2008;15:1179-1184.

78. Goodman SN. Toward evidence-based medical statistics 2: the Bayes factor. Ann Intern Med. 1999;130:1005-1013.

79. Logothetis NK. What we can do and what we cannot do with fMRI. Nature. 2008;453:869-878.

80. England MA, Wakely J. Color Atlas of the Brain and Spinal Cord. 2nd ed. London, UK: Mosby; 2005. 


\section{Appendix \\ Reverse inference model}

Following the example given in the text, the events are denoted as $N$ (eg, nucleus accumbens activation) and $R$ (eg, reward process or task) assuming that the conditional probability of $N$ given $R, P(N \mid R)$, and the conditional probability of $N$ in the absence of $R, P(N \mid \bar{R})$, are known (the bar means not $R$ ). $P(R)$ is the prior probability. Applying Bayes and elementary probability rules, one has

$$
P(R \mid N)=\frac{P(N \mid R) P(R)}{P(N)}
$$

and

$$
P(N \mid \bar{R})=\frac{P(\bar{R} \mid N) P(N)}{P(\bar{R})}=\frac{[1-P(R \mid N)] P(N)}{1-P(R)} .
$$

The latter equation is solved for $P(N)$ and inserted in the first, and, after some algebra one obtains the posterior probability

$$
P(R \mid N)=\frac{P(N \mid R) P(R)}{P(R)[P(N \mid R)-P(N \mid \bar{R})]+P(N \mid \bar{R})} .
$$

Defining the ratio of probabilities $Q=P(N \mid \bar{R}) / P(N \mid R)$, one has

$$
P(R \mid N)=\frac{P(R)}{P(R)[1-Q]+Q} .
$$

This formula can be understood as a means of updating one's prior beliefs based on new evidence, and this change depends upon the selectivity of the empirical evidence $Q$. The significance of change can be assessed using the Bayes factor. $^{78}$

$$
B=\frac{\operatorname{odd}(P(R \mid N))}{\operatorname{odd}(P(R))}, \text { with odds }(p)=\frac{p}{1-p} .
$$

Using the expression for $P(R \mid N)$, one obtains

$$
B=\frac{1}{Q}
$$

The Bayes factor is not a probability and cannot be used directly as a means of statistical inference. Instead, one adheres to the convention that that a factor between 1 and 3 represents weak evidence, between 3 and 10 reflects moderate evidence, and greater than 10 reflects strong evidence. ${ }^{69,78}$ Note a small $Q$ value implies that it is unlikely to observe $\mathrm{N}$ in the absence of $R$, in which case $P(N \mid R)$ becomes essentially independent of $P(R)$

$$
P(R \mid N) \sim \frac{P(R)}{P(R)+Q} \sim 1, \quad \text { for } P(R)>Q .
$$

Neuroscience and Neuroeconomics

\section{Publish your work in this journal}

Neuroscience and Neuroeconomics is an international, peerreviewed, open access journal focusing on the identification of brain structures and measurement of neural activity related to behavior, behavioral predictions, and decision making in health and disease.

\section{Dovepress}

Visit http://www.dovepress.com/testimonials.php to read real quotes from published authors. 